\title{
O SUJEITO HISTÓRICO DO CONHECIMENTO - AS CONDIÇÕES ECONÔMICAS, SOCIAIS E POLITICAS COMO ESPAÇOS OBRIGATÓRIOS DE PRÁTICAS CONFLITIVAS DO DISCURSO FILOSÓFICO
}

\author{
Ivo José Kunzler \\ Recibido: Agosto 28 de 2015 \\ Aprobado: Noviembre 25
}

\begin{abstract}
RESUMO
Por intermédio deste artigo, se pretende investigar como as práticas sociais podem chegar a engendrar os domínios de saber que não somente fazem aparecer novos objetos, novos conceitos, novas técnicas, mas também fazem nascer formas totalmente novas de sujeitos e de sujeitos de conhecimento. Desta forma, se pode afirmar, que o próprio sujeito de conhecimento tem uma história, a relação do sujeito com o objeto, ou, mais claramente, a própria verdade tem uma história.
\end{abstract}

Palavras-chave: Sujeito, Conhecimento, Conflito, História

\section{HISTORICAL KNOWLEDGE SUBJECT - THE ECONOMIC CONDITIONS, AND SOCIAL POLICIES AS SPACE MANDATORY PRACTICES CONFLICTING OF PHILOSOPHICAL SPEECH}

\begin{abstract}
Through this article, intended to investigate how social practices can engender the domains to know that not only do appear new objects, new concepts, new techniques, but also make entirely new forms of born subject and subject of knowledge. In this way, one can claim that the very subject of knowledge has a story, the relationship of the subject with the object, or, more clearly, the truth itself has a history

* Kunzler, Ivo José. Advogado; Graduado em Ciências Jurídicas e Sociais pela UFPEL; Mestre em Direito Tributário e Constitucional pela UNISC; Especialista em Direito Tributário pelo IBET; Doutorando na UBA em Direito Constitucional.E-mail: ivokunzler@kunzleradvogados.com.br
\end{abstract}


Key-word: Subject. Knowledge. Conflict. History

\section{EL SUJETO HISTÓRICO DEL CONOCIMIENTO - LAS CONDICIONES ECONÓMICAS, SOCIALES Y POLÍTICAS COMO ESPACIOS OBLIGATORIOS DE PRÁCTICAS CONFLICTIVAS DEL DISCURSO FILOSÓFICO. IVO JOSE KUNZLER}

\section{RESUMEN}

A través de este artículo, se quiere investigar cómo las prácticas sociales pueden llegar a engendrar campos del saber que no sólo hacen nacer nuevos objetos, nuevos conceptos, nuevas técnicas, sino también dar a luz formas totalmente nuevas de sujetos y de sujetos del conocimiento. Por lo tanto, se puede decir que el propio sujeto del conocimiento tiene una historia, la relación del sujeto con el objeto, o más claramente, la verdad misma tiene una historia.

Palabras clave: Sujeto, Conocimiento, Conflicto, Historia

\section{INTRODUÇÃO}

Nesta investigação a que estamos nos propondo, o primeiro aspecto a ser analisado é o fato histórico, quer dizer: como se puderam formar domínios de saber a partir de práticas sociais? Segundo Foucault a questão deverá ser assim proposta: existe uma tendência que poderíamos chamar, um tanto ironicamente, de marxismo acadêmico, que consiste em procurar de que maneira as condições econômicas de existência podem encontrar na consciência dos homens o seu reflexo e expressão. (Foucault, 2005, p. 8)

Pela importância histórica, tanto nos negócios como na religião, e em todos os tempos, não é demais fazer desde logo uma referência a comunidade judaica, nos termos que Pirenne propõe:

Por mais que se procure mercadores profissionais, não se encontra nenhum, ou antes, encontram-se unicamente judeus. Somente eles, a partir da época carolíngia, exerciam com regularidade o comércio, a tal ponto que, no idioma daquele tempo, a palavra judaeus e a palavr4a mercator são 
quase sinônimas. Alguns estabeleceram-se no sul da França, porém a maioria vinha dos países muçulmanos do Mediterrâneo, de onde se transferiram, passando pela Espanha, ao ocidente e ao norte da Europa. Eram todos eles radamitas, perpétuos viajores, graças aos quais se manteve um contato superficial com as regiões orientais. (Pirenne, 1968, p. 17)

Por outro lado, segundo Foucault, a análise tradicional como o marxismo universitário da França e da Europa, apresenta a sociedade e seus conflitos, estaria contaminado, com um defeito muito grave, isto é, o de supor, no fundo que o sujeito humano, o sujeito de conhecimento, as próprias formas do conhecimento seriam de certo modo dados a priori, previa e definitivamente, e que as condições econômicas, sociais e políticas da existência do sujeito não fariam mais do que depositar-se ou imprimir-se neste sujeito humano, como algo definitivamente dado. Apenas para confirmar a afirmação acima, pode-se citar passagem de Marx, na obra "A questão judaica", ao afirmar que:

Costuma-se dizer que o homem é um ser social, pois vive em sociedade e recebe suas influências culturais específicas. O homem, segundo Marx:

(...) é o mundo dos homens, o Estado, a sociedade". Mas ele também é um ser histórico, que vive em determinada época e assimila as ideias que predominam durante o período da sua vida, bem como aquelas que o antecederam, pois que, ao nascer, ele se torna herdeiro de todo o patrimônio cultural da humanidade. (Marx, 1985, p. 7)

Segundo Touraine, a ideia de sociedade que definiu a modernidade foi a separação entre a ordem do mundo, do seu sentido ou mesmo da intenção que a criou, no caso das religiões, monoteístas, e a consciência humana; Descartes dizia: entre a extensão e a alma. Em termos mais atuais, dizemos que a modernidade se define pela separação entre a racionalização, como modalidade de ação sobre a natureza, e o individualismo moral. (Touraine, 1998, p. 7) Com estes pontos de vista, esta investigação pretende demonstrar que as práticas sociais tem a possibilidade de engendrar domínios de saber que além de fazerem aparecer novos objetos, novos conceitos, novas técnicas, fazem surgir e nascer formar completamente novas de sujeitos, aqui entendidos como sujeitos de conhecimento. Disto se pode inclusive afirmar com Foucault, que o próprio sujeito de conhecimento teria uma história, a relação do 
sujeito com o objeto, ou, mais explicitamente, que a própria verdade teria uma história. (Foucault, 2005, p. 8)

Dentro desta linha de pensamento, se pretende demonstrar a formação durante o século XIX, de um determinado saber do homem, de sua individualidade, do indivíduo normal ou anormal, dentro ou fora da regra, saber este que, na verdade, nascera das práticas sociais, das práticas sociais do controle e da vigilância. E neste sentido, Foucault afirma que de certa maneira, esse saber não se teria imposto a um sujeito de conhecimento qualquer, não teria sido proposto a ele, nem se teria imprimido nele, mas se teria feito nascer a partir de um tipo absolutamente novo de sujeito de conhecimento, e disto se poderia dizer que a história dos domínios do saber em relação com as práticas sociais, exclui a preeminência de um sujeito de conhecimento dado definitivamente e a priori. (Foucault, 2005, p. 8)

Ao ensejo, é oportuno lançar a ideia de Kuhn, segundo que, o historiador da ciência que examinar as pesquisas do passado a partir da perspectiva da historiografia contemporânea pode sentir-se tentado a proclamar que, quando mudam os paradigmas, muda com eles o próprio mundo. Guiados por um novo paradigma, os cientistas adotam novos instrumentos e orientam seu olhar em novas direções. E o que é ainda mais importante: "durante as revoluções, os cientistas veem coisas novas e diferentes quando, empregando instrumentos familiares, olham para os mesmos pontos já examinados anterior 4 mente, é como se a comunidade profissional tivesse sido subitamente transportada para um novo planeta, onde objetos familiares são vistos sob uma luz diferente e a eles se agregam objetos desconhecidos. (Kuhn, 2001,p. 146)

Por isso, não é demasiado invocar Descartes, quando este afirma: você já ficou sem saber o que pensar enquanto alguém argumentava que, para Platão, a liberdade era tal, coisa, ou que, para Kant, a natureza humana deveria ser de tal modo? Sabe por que isso acontece? Porque precisamos buscar em Platão o conceito de liberdade para Platão, e buscar em Kant a definição de natureza humana para Kant. (Descartes, 2006, p. 5)

Este será o esforço, e esta é a temática de investigação e abordagem que se está envolvido neste trabalho, e que a seguir se irá aprofundar, a partir, inclusive da citação de outros autores e obras, mas fundamentalmente do pensamento de Foucault, o que este pensa sobre saber e poder e sobre a verdade, a partir de todos os conflitos vividos em sociedade. 


\section{O SUJEITO HISTÓRICO PENSANTE, ATOR NO PROCESSO DE CONSTRUÇÃO DO CONHECIMENTO, NUM AMBIENTE DE CONFLITO}

É importante, para estudar o sujeito do conhecimento, isto é, parece-nos importante reconhecer com Foucault que há algum tempo no passado, teria sido original e importante dizer e mostrar que o que estava sendo feito com a linguagem - com a poesia, literatura, filosofia, e com o discurso em geral - obedecia a um certo número de leis ou regularidades internas - as chamadas leis e regularidades da linguagem. Considerando este aspecto, o caráter linguístico dos fatos de linguagem teria sido uma descoberta de importância em determinada época da história. (Foucault, 2005, p. 9)

Chegara, no entanto, um novo momento da história, onde este fatos de discurso seriam considerados não apenas em seu caráter ou aspecto linguístico, mas, em certa medida, o que pode-se dizer, inspirados em pesquisas realizadas por investigadores anglo-americanos, como verdadeiros jogos (games), isto é jogos estratégicos, de ação e reação, de perguntas e respostas, de dominação e de esquiva ou sujeição, como uma verdadeira luta. assim, o discurso seria esse conjunto regular de fatos linguísticos em determinado nível, e ao mesmo tempo seriam polêmicos e estratégicos em outro nível.

Segundo Foucault, é neste quadrante da investigação acerca a teoria do sujeito, que ocorreram as mais profundas modificações e renovações ao longo dos últimos anos, num grande número de teorias e práticas, e foram mesmo profundas por outras, alterando-se suas práticas e técnicas, e entre as quais se pode citar a psicanálise, que foi certamente a prática e a teoria que reavaliou da maneira mais fundamental a prioridade, um tanto sagrada, conferida ao sujeito, que se estabelecera no pensamento ocidental desde Descartes. (Foucault, 2005, p. 10)

Neste sentido, veja-se a seguinte afirmação de Foucault, ao sentenciar o caráter desde movimento:

Há dois ou três séculos, a filosofia ocidental postulava, explicita ou implicitamente, o sujeito como fundamento, como núcleo central de todo conhecimento, como aquilo em que e a partir de que a liberdade se revelava e a verdade podia explodir. Ora, parece-me que a psicanálise pôs em questão, de maneira enfática, essa posição absoluta do sujeito. Mas se 
a psicanálise o fez, em compensação, no domínio do que poderíamos chamar teoria do conhecimento, ou no da epistemologia, ou no da historia das ciências ou ainda no da história das ideias, parece-me que a teoria do sujeito permaneceu ainda muito filosófica, muito cartesiana e kantiana, pois ao nível de generalidade em que me situo, não faço, por enquanto, diferença entre as concepções cartesiana e kantiana. (Foucault, 2005, p. 10)

Acentua ainda Foucault, em continuidade a seu pensamento acima iniciado, e sobremaneira enfático:

Atualmente, quando se faz história - história das ideias, do conhecimento ou simplesmente história - atemos-nos a esse sujeito de conhecimento, a este sujeito da representação, como ponto de origem a partir do qual o conhecimento é possível e a verdade aparece. Seria interessante tentar ver como se dá, através da história, a constituição de um sujeito que não é dado definitivamente, que não é aquilo a partir do que a verdade se da na história, mas de um sujeito que se constitui no interior mesmo da história, e que é a cada instante fundado e refundado pela história. (Foucault, 2005, p. 10)

Alerta o autor, que seria em direção desta crítica radical do sujeito humano, do sujeito do conhecimento, pela história que deveríamos nos dirigir. Adverte ainda, que poderíamos verificar ainda hoje, dentro da tradição universitária ou acadêmica do marxismo, uma certa concepção filosoficamente tradicional do sujeito, que ainda não teria sido abandonada ou revista, e que segundo Foucault, deveria já ter sido feito, para se ter: a constituição histórica de um sujeito de conhecimento através de um discurso tomado como um conjunto de estratégias que faze parte das praticas sociais. (Foucault, 2005, p. 10)

Alerta ainda Foucault, que entre as práticas sociais em que a análise histórica permite localizar a emergência de novas formas de subjetividade, as práticas jurídicas, ou mais precisamente, as práticas judiciárias, estariam entre as mais importantes. Neste sentido afirma Foucault:

A hipótese que gostaria de propor é que, no fundo, há duas histórias da verdade. A primeira é uma espécie de história interna da verdade, a história de uma verdade que se corrige a partir de seus próprios 
princípios de regulação: é a história da verdade tal como se faz na ou a partir da história das ciências.

Por outro lado, parece-me que existem, na sociedade, ou pelo menos, em nossas sociedades, vários outros lugares onde a verdade se forma, onde um certo número de regras de jogo são definidas - regras de jogo a partir das quais vemos nascer certas formas de subjetividade, certos domínios de objeto, certos tipos de saber - e por conseguinte podemos, a partir dai, fazer uma história externa, exterior, da verdade. (Foucault, 2005, p. 11)

Neste contexto, as práticas judiciárias - a maneira pela qual, entre os homens, se arbitram os danos e as responsabilidades, o modo pelo qual, na história do Ocidente, se concebeu e se definiu a maneira como os homens podiam ser julgados em função dos erros que haviam cometido, a maneira como se impôs a determinados indivíduos a reparação de algumas de suas ações e a punição de outras, todas essas regras ou, se quiserem, todas essas práticas regulares, é claro, mas também modificadas sem cessar através da história - segundo Foucault, parecem, uma das formas pelas quais nossa sociedade definiu tipos de subjetividade de conhecimento, formas de saber e, por conseguinte, relações entre o homem e a verdade que merecem ser estudas. A propósito, é dentro desta visão geral, que se encontram as formas jurídicas, particularmente no campo do direito penal, como lugar de origem, de um determinado número de formas de verdade.

Dentro desta lógica de pensar, pode-se evidenciar, como certas práticas, certas formas de verdade podem ser definidas a partir da prática penal. Nisto se pode incluir, o chamado inquérito, tal como é e como foi praticado pelos filósofos do século XV até o século XVIII, o que se verifica também em cientistas, sejam eles geógrafos, botânicos, zoólogos, economistas, pois que esta é uma forma bem característica da apuração da verdade em nossas sociedades.

Sobre o assunto, poderíamos nos perguntar com Foucault, onde encontramos a origem do inquérito? E encontraríamos a seguinte resposta: nós a encontramos em uma prática política e administrativa determinada, mas também na prática judiciária. E teria sido segundo o autor, no meio da Idade Média que o inquérito aparecera como forma de pesquisa da verdade no interior da ordem jurídica. Teria sido utilizada, para saber-se exatamente quem fez o que, em que condições e em que momento temporal, que no Ocidente se teria elaborado estas complexas técnicas do inquérito, que puderam, em seguida, serem utilizadas na 
ordem científica e na ordem da reflexão filosófica. (Foucault, 2005, p. 12)

Por outro lado, e não diferente, no século XIX se inventaram, a partir de problemas jurídicos e judiciários, penais, formas de análise muito curiosas que poderíamos chamar de exame, e não mais de inquérito. Estas formas, por sua vez, deram origem à Sociologia, à Psicologia, à Psicopatologia, à Criminologia, à Psicanálise. Do que se pode concluir,, que estas formas nasceram de uma ligação direta e umbilical com a formação de um certo número de controles políticos e sociais no momento da formação da sociedade capitalista que conhecemos, no final do século XIX.

Parece oportuno aqui, neste momento, apresentar o pensamento de Engels, a cerca da moral e do direito, das chamadas verdades eternas, onde este autor faz severas críticas, ao perguntar: o pensamento humano é soberano? e em seguida responde assim:

Antes de responder sim ou não, é preciso primeiramente saber o que é, na realidade, o pensamento humano. É o pensamento de um só homem? Não. Ele não existe senão como pensamento concreto de muitos milhares de milhões de homens passados, presentes e futuros. Assim, pois, quando eu digo que esse pensamento de todos os homens, inclusive os vindouros, sintetizado no meu espírito, é soberano, capaz de conhecer, de modo abstrato, o mundo real, desde que a humanidade subsista o tempo necessário para isso e que não se produza, nem nos órgãos nem nos objetos do conhecimento, modificação capaz de limitar esse conhecimento, estarei dizendo uma coisa banal e, além disso, estéril. Porque o resultado mais precioso dessa ideia seria tornarmo-nos extremamente desconfiados quanto aos nossos conhecimentos atuais, posto que estamos, segundo toda a probabilidade, ainda quase no inicio da historia da humanidade, tendo as gerações que nos corrigirão de ser seguramente muito mais numerosas que aquelas cujos conhecimento - não poucas vezes um olímpico desprezo - somos capazes de corrigir. (Engels, 1979, p. 72)

Numa outra passagem de seus estudos, Engels fala da ação humana relacionada à natureza a terra:

Mas toda a ação dos animais, obedecendo a um plano, não conseguiu imprimir a terra o selo de sua vontade. Somente o homem foi capaz de fazer isso. O animal apenas utiliza a Natureza, nela produzindo modificações somente por sua 
presença. O homem a submete, pondo-a a serviço de seus fins determinados, imprimindo-lhe as modificações que julga necessárias, isto é, domina a natureza. E esta é a diferença essencial e decisiva entre o homem e os ademais animais; e, por outro lado, é o trabalho que determina essa diferença. (Engels, 1979, p. 223)

Por outro lado ainda, e numa formulação reflexiva diferente, poder-seia, buscar no pensamento de Nietzsche, um tipo de discurso em que se faz uma análise histórica da própria formação do sujeito, e disto, uma análise histórica do nascimento de um certo tipo de saber, sem nunca admitir a preexistência de um sujeito de conhecimento. Esta formulação poderá servir de modelo para a análise do que esta se propondo aqui, nesta investigação. Como ponto de partida desta forma de pensar e investigar, busca-se novamente em Foucault, a citação da obra de Nietzsche, num texto datado de 1873 , em publicação póstuma, que aquele entende como adequada para esclarecer o ponto:

Em algum ponto perdido deste universo, cujo clarão se estende a inúmeros sistemas solares, houve, uma vez, um astro sobre o qual animais inteligentes inventaram o conhecimento. Foi o instante da maior mentira e da suprema arrogância da história universal. (Foucault, 2005, p. 13)

Observe-se com atenção o conteúdo do texto acima, uma mistura de sátira e crítica reveladora da oposição ao pecado original.

O texto de Nietzsche é profundamente revelador, extremamente rico e de difícil compreensão inicial e de quase não aceitação temporal. Advertese, pois, que não se pode esquecer, que estávamos em 1873, em pleno contexto e vigor do pensamento e do auge do ideário de Kant, senão vivendo pelo menos o neokantismo, e desta forma, a ideia de que o tempo e o espaço podem preexistir ao conhecimento, ou a ideia de que o tempo e o espaço não são formas do conhecimento, mas pelo contrário, como afirmado por Nietzsche, espécies de rochas primitivas sobre as quais o conhecimento vem se fixar, é para esta época absolutamente inadmissível. Aqui toma-se por capricho a abordagem que Foucault propõe da polêmica proposta por Nietzsche, transcrevendo-a para melhor compreensão:

É a isso que gostaria de me ater, fixando-me primeiramente ao próprio termo invenção. Nietzsche afirma que, em um determinado ponto do 
tempo e em um determinado lugar do universo, animais inteligentes inventaram o conhecimento; a palavra que emprega, invenção - o termo alemão é Erfindung - é frequentemente retomada em seus textos, e sempre com sentido e intenção polêmicos. Quando fala de invenção, Nietzsche tem sempre em mente uma palavra que opõe a invenção, a palavra origem. Quando diz invenção é para não dizer origem; quando diz Erfindung é para não dizer Ursprung.

Tem-se um certo número de provas disto. Apresentarei duas ou três. Por exemplo, em um texto que é, segundo creio, da Gaia Ciência, em que fala de Schopenhauer reprovando-lhe sua análise da religião, Nietzsche diz que Shopenhauer cometeu o erro de procurar a origem - Ursprung - da religião em um sentimento metafísico, que estaria presente em todos os homens e conteria, por antecipação, o núcleo de toda religião, seu modelo ao mesmo tempo verdadeiro e essencial. Nietzsche afirma: eis uma análise da história da religião que é totalmente falsa, pois admitir que a religião tem origem em um sentimento metafísico significa, pura e simplesmente, que a religião já estava dada, ao menos em estado implícito, envolta nesse sentimento metafísico. Ora, diz Nietzsche, a historia não é isso, não é dessa maneira que se faz história, não é dessa maneira que as coisas se passaram. Pois a religião não tem origem, não tem Ursprung, ela foi inventada, houve uma Erfindung da religião.

Em um dado momento, algo aconteceu que fez aparecer a religião. A religião foi fabricada. Ela não existia anteriormente. (Foucault, 2005, p. 14)

De forma que, entre a grande continuidade da Ursprung descrita por Schopenhauer e a ruptura que caracteriza a Erfindung de Nietzsche há uma oposição fundamental, senão abissal. Continua Focault, em sua caminhada pelo pensamento de Nietzsche, ao referir-se de que, quando se fala de poesia, sempre quando referido a obra Gaia Ciência, Nietzsche teria afirmado haver quem procure uma origem, Ursprung, da poesia, quando na verdade não há Ursprung da poesia, há somente uma invenção da poesia. De tal forma, que um dia alguém teria tido a ideia bastante curiosa de utilizar um certo número de propriedades rítmicas ou musicais da linguagem para falar, para impor suas palavras, para estabelecer através de suas palavras uma certa relação de poder sobre os outros. Também a poesia teria sido inventada ou fabricada, desta mesma forma. (Foucault, 2005, p. 15)

Segundo Foucault, ainda no mesmo texto, existe uma famosa passagem no final do primeiro discurso de A Genealogia da Moral em que 
Nietzsche se refere a essa espécie de grande fábrica, de grande usina, em que se produz o ideal. O ideal não tem origem. Ele também foi inventado, fabricado, produzido por uma sério de mecanismos, de pequenos mecanismos. De forma que, a invenção - Erfindung - para Nietzsche é, por um lado, uma ruptura, por outro, algo que possui um pequeno começo, baixo, mesquinho, inconfessável. Este é o ponto crucial da Erfindung. Foi por obscuras relações de poder que a poesia foi inventada. Foi igualmente por puras obscuras relações de poder que a religião foi inventada.

Desta formulação encontrada no pensamento de Nietzsche, aqui transcrito e trazido a comentário por Focault, se pode chegar a conclusão com este último de que o conhecimento foi inventado, senão vejamos:

O conhecimento foi, portanto, inventado. Dizer que ele foi inventado é dizer que ele não tem origem. É dizer, de maneira mais precisa, por mais paradoxal que seja, que o conhecimento não está em absoluto inscrito na natureza humana. $\mathrm{O}$ conhecimento não constitui o mais antigo instinto do homem, ou, inversamente, não há no comportamento humano, no apetite humano, no instinto humano, algo, como um germe do conhecimento. De fato, diz Nietzsche, o conhecimento tem relação com os instintos, mas não pode estar presente neles, nem mesmo por ser um instinto entre os outros.

O conhecimento é simplesmente o resultado do jogo, do afrontamento, da junção, da luta e do compromisso entre os instintos. É porque os instintos se encontram, se batem e chegam, finalmente, ao término de suas batalhas, a um compromisso, que algo se produz. Este algo é o conhecimento. (Foucault, 2005, p. 16)

Disto se pode concluir que o conhecimento não é da mesma natureza que os instintos, não é como que um refinamento dos próprios instintos. $\mathrm{O}$ conhecimento tem por fundamento, como base de fundo, e por ponto de partida os instintos sim, mas instintos em confronto entre si, em luta, de que ele é apenas o resultado da batalha, em sua superfície emanada. Poder-se-ia ainda dizer, que o conhecimento seria emanação, efeito, de um clarão, como uma luz que se irradia mas que é produzido por mecanismos ou realidades que são de natureza totalmente diversa dele. De forma que, o conhecimento é o efeito dos instintos, é como um lance de sorte, ou como o resultado de um longo compromisso, senão uma batalha entre os mesmos. Parafraseando Nietzsche, se poderia dizer que 
o conhecimento seria uma "centelha entre duas espadas", mas que não é do mesmo ferro que as duas espadas.

Neste sentido, afirma Foucault que o conhecimento seria um conhecimento de superfície, não delineado de antemão na natureza humana, pois que o conhecimento vem atuar diante dos instintos, acima deles, no meio deles; ele os comprime, traduz um certo estado de tensão ou de apaziguamento entre os instintos. E insiste o autor, em afirmar que não se poderia deduzir o conhecimento, de maneira analítica, segundo uma espécie de derivação natural. Quer dizer, que não se pode de modo necessário, deduzi-lo dos próprios instintos. O conhecimento, no fundo, não faz parte da natureza humana. É a luta, o combate, o resultado do combate e consequentemente o risco e o acaso que vão dar lugar ao conhecimento. O conhecimento não é instintivo, é contra instintivo, assim como ele não é natural, é contra natural. (Foucault, 2005, p. 17) E disto conclui Foucault que:

Este é o primeiro sentido que pode ser dado á ideia de que o conhecimento é uma invenção e não tem origem. Mas o outro sentido que pode ser dado a esta afirmação seria o de que o conhecimento, além de não estar ligado a natureza humana, de não derivar da natureza humana, nem mesmo é aparentado, por um direito de origem, com o mundo a conhecer. (Foucault, 2005, p. 17)

Disto se poderá concluir, segundo o que nos ensina Nietzsche conforme acima exposto, que não há nenhuma semelhança, nenhuma afinidade prévia entre conhecimento e essas coisas que seria necessário conhecer. Poder-seia dizer isso em termos kantianos rigorosos, que as condições de experiência e as condições do objeto de experiência são totalmente heterogêneas.

É pois neste ponto que se encontra a grande ruptura com o que havia sido tradição da Filosofia ocidental, e onde até mesmo Kant foi um dos primeiros a dizer explicitamente que as condições de experiência e do objeto de experiência eram idênticas. Neste ponto, Nietzsche pensa exatamente ao contrário, isto é, que entre conhecimento e mundo a conhecer há tanta diferença quanto entre conhecimento e natureza humana. Temos então, uma natureza humana, um mundo, e algo entre os dois que se chama o conhecimento, não havendo entre eles nenhuma afinidade, semelhança ou mesmo elos de natureza.

Neste sentido afirma ainda Nietzsche frequentemente, conforme citação de Foucault, de que o conhecimento não teria relação de afinidade com o 
mundo a conhecer, o que está em Gaia Ciência (parágrafo 109): "o caráter do mundo é o de um caos eterno; não devido á ausência de necessidade, mas devido à ausência de ordem, de encadeamento, de formas, de beleza e de sabedoria. (Foucault, 2005, p. 18)

Continua Foucault com a afirmação de que o mundo não procura absolutamente imitar o homem, ele ignora toda lei, e para isso sentencia dizendo que:

Abstenhamo-nos de dizer que existem leis da natureza. É contra um mundo sem ordem, sem encadeamento, sem formas, sem beleza, sem sabedoria, sem harmonia, sem lei, que o conhecimento tem de lutar. É com ele que o conhecimento se relaciona. Não há nada no conhecimento que o habilite, por um direito qualquer, a conhecer esse mundo. não é natural à natureza ser conhecida. (Foucault, 2005, p. 18)

Pode-se afirmar então ainda com Foucault:

Assim como entre instinto e conhecimento encontramos não uma continuidade, mas uma relação de luta, de dominação, de subserviência, de compensação etc., da mesma forma, entre o conhecimento e as coisas, que o conhecimento tem a conhecer não pode haver nenhuma relação de continuidade natura.l. Só pode haver uma relação de violência, de dominação, de poder e de força, de violação. O conhecimento só pode ser uma violação das coisas a conhecer e não percepção, reconhecimento, identificação delas ou com elas. (Foucault, 2005, p. 18)

Conforme se pode perceber, há nesta análise de Nietzsche, uma dupla ruptura com a tradição da Filosofia ocidental, reveladora de grande importância, e cuja lição precisamos conservar. A primeira ruptura a ser apontada é a ruptura entre o conhecimento e as coisas. o que, pois que efetivamente dever-se-ia perguntar, o que, na Filosofia ocidental assegurava que as coisas a conhecer e o próprio conhecimento estavam em relação de continuidade? O que assegurava ao conhecimento o poder de conhecer bem as coisas do mundo e de não cair indefinidamente no erro, ilusão, arbitrariedade? O que garantia isto na Filosofia ocidental, senão Deus? 
Afirma Foucault, que Deus, certamente, desde Descartes, para não se ir mais além, e mesmo Kant, é esse principio que assegura haver uma harmonia entre o conhecimento e as coisas a conhecer. Para demonstrar que o conhecimento era o conhecimento fundado em verdades, nas coisas existentes do mundo, e para isso, Descartes precisou afirmar a existência de Deus. (Foucault, 2005, p. 19)

Observemos então a seguinte afirmação de Foucault: se não existe mais relação entre o conhecimento e as coisas a conhecer, se a relação entre o conhecimento e as coisas conhecidas é arbitrária, de poder e de violência, a existência de Deus não é mais indispensável no centro do sistema de conhecimento. Assevera o autor ainda, que na mesma passagem que cita, da Gaia Ciência, em que evoca a ausência de ordem, de encadeamento, de formas, de beleza do mundo, Nietzsche teria perguntado precisamente o seguinte: "quando cessaremos de ser obscurecidos por todas essas sombras de deus, quando conseguiremos desdivinizar completamente a natureza?" (Foucault, 2005, p. 19)

E teria sido desta forma que a ruptura da teoria do conhecimento com a teologia se fizera começar de maneira estrita com uma análise como esta de Nietzsche.

Numa segunda ruptura a ser apontada, num segundo lugar, poder-se-ia dizer que, se é verdade por um lado, que entre o conhecimento e os instintos - em tudo o que se faz, em tudo o que trama o animal humano há sempre ruptura, relações de dominação e subserviência, e relações de poder, o que faria desaparecer então, não mais o Deus, mas o sujeito completo em sua unidade e soberania.

De forma que, em se remontando à tradição filosófica a partir de Descartes, para não se ir mais longe, podemos ver que a unidade do sujeito humano era sempre assegurada pela continuidade que ia do desejo ao conhecer, do instinto ao saber, do corpo à ve4rdade. E tudo isso, segundo Foucault, assegurava neste tempo, a existência do sujeito. Neste sentido, argumenta Focault dizendo: se é verdade que há, por um lado, os mecanismos do instinto, os jogos do desejo, os afrontamentos da mecânica do copo e da vontade e, por outro lado, num nível de natureza totalmente diferente, o conhecimento, então não se tem mais necessidade da unidade do sujeito humano. Poderíamos admitir sujeitos, ou poderíamos admitir que o sujeito até mesmo não existe. Eis em que o texto de Nietzsche citado por Foucault, e que é consagrado à invenção do conhecimento, parece estar em franca ruptura com a tradição da filosofia 
mais antiga e a mais estabelecida da filosofia ocidental. (Foucault, 2005, p. 20)

Observe-se no que insiste Foucault e em que sentido, ao afirmar que, quando Nietzsche diz que o conhecimento é o resultado dos instintos, mas não é um instinto, nem deriva diretamente dos instintos, pergunta, que queria dizer ele exatamente, e como concebe este curioso mecanismo pela qual os instintos, sem ter nenhuma relação de natureza com o conhecimento, podem por seu simples, jogo, produzir, fabricar, inventar um conhecimento que nada tem a ver com eles? Focault continua, dizendo que esta seria uma segunda série de problemas que ele gostaria de abordar:

Existe um texto da Gaia Ciência (parágrafo 333) que podemos considerar como uma das análises mais estritas de Nietzsche fez dessa fabricação, dessa invenção do conhecimento. Nesse longo texto intitulado - "Que significa conhecer?" - Nietzsche retoma um texto de Spinoza, onde este opunha intelligere, compreender, a ridere, lugere, detestari. Spinoza dizia que, se quisermos compreender as coisas, se quisermos efetivamente compreendê-las em sua natureza, em sua essência e portanto em sua verdade, é necessário que nos abstenhamos de rir delas, de deplorá-las ou de detestá-las. Somente quando estas paixões se apaziguarem podemos enfim compreender. Nietzsche diz que isto não somente não é verdade, mas é exatamente o contrário que acontece. Intelligere, compreender, não é nada mais que um certo jogo, ou melhor, o resultado de um certo jogo, de uma certa composição ou compensação entre ridere, rir, lugere, deplorar, e detestari, detestar. (Foucault, 2005, p. 20)

De sua vez, a explicação que encontramos em Nietzsche sobre o tema acima, é de que somente compreendemos porque há por trás de tudo isso, o jogo e a luta desses três instintos, desses três mecanismos, ou dessas três paixões que são rir, o deplorar e o detestar (o ódio).

Foucault, por sua vez vê nestas três paixões, ou nestes três impulsos, rir, detestar e deplorar, uma coisa em comum, o fato de serem uma maneira não de se aproximar do objeto, de se identificar com ele, mas, ao contrário, de conservar o objeto à distância, de se diferenciar dele ou de se colocar em ruptura com ele, de se proteger dele pelo riso, desvalorizálo pela deploração, afastá-lo e eventualmente destruí-lo pelo ódio. Portanto, segundo Foucault, todos esses impulsos que estão na raiz do conhecimento e o produzem têm em comum o distanciamento do objeto, 
uma vontade de se afastar dele e de afastá-lo ao mesmo tempo, enfim de destruí-lo. Através do conhecimento há uma vontade, sem duvida obscura, não de trazer o objeto para si, de se assemelhar a ele, mas ao contrário, uma vontade obscura de se afastar dele e de destruí-lo, maldade radical do conhecimento. (Foucault, 2005, p. 21)

Disto decorre, segundo Foucault uma ideia importante, a de que esses impulsos - rir, deplorar, detestar - são todos da ordem das más relações. Constata-se isso, pois que, atrás do conhecimento, na raiz do conhecimento, Nietzsche não coloca uma espécie de afeição, de impulso ou de paixão que nos faria gostar do objeto a conhecer, mas, ao contrário, nos coloca diante de impulsos que nos colocam em posição de ódio, desprezo, ou mesmo de temor diante de coias que são ameaçadoras e presunçosas. (Foucault, 2005, p. 21)

E aqui parece que nosso problema de investigação começa a se desvendar claramente diante dos olhos, pois que, conforme afirma Foucault:

Se esses três impulsos - rir, deplorar e odiar - chegam a produzir o conhecimento não é, segundo Nietzsche, porque se apaziguaram, como em Spinoza, ou se reconciliaram, ou chegaram a uma unidade. É, ao contrário, porque lutaram entre si, porque se confrontaram. É porque esses impulsos se cobateram, porque tentaram, como diz Nietzsche, prejudicar uns aos outros, é porque estão em estado de guerra, em uma estabilização momentânea desse estado de guerra, que eles chegaram a uma espécie de estado, de corte onde finalmente o conhecimento vai aparecer como "a centelha entre duas espadas". (Foucault, 2005, p. 22)

E disto conclui Foucault, que não pode haver, no conhecimento uma adequação ao objeto, uma relação de assimilação, mas, ao contrário, uma relação de distância e dominação; não há no conhecimento algo como felicidade e amor, mas ódio e hostilidade; não há unificação, mas sistema precário de poder.

\section{CONCLUSÃO}

Observe-se no problema acima proposto para investigação, que o conhecimento tem sempre um caráter prospectivo porque há sempre 
uma batalha que o envolve, e porque o conhecimento é o efeito final deste confronto, o resultado desta batalha de campo.

Segundo Focault, é por isso que encontramos em Nietzsche a ideia, que volta constantemente, de que o conhecimento é ao mesmo tempo o que há de mais generalizante e de mais particular. O conhecimento esquematiza, ignora as diferenças, assimila as coisas entre si, e isto sem nenhum fundamento em verdade. Devido a isso, o conhecimento é sempre um desconhecimento. Por outro lado, é sempre algo que visa, maldosa, insidiosa e agressivamente, indivíduos, coisa, situações. (Foucault, 2005, p. 25 ). E neste sentido arremata Foucault, afirmando que somente há conhecimento na medida em que, entre o homem e o que ele conhece, se estabelecer, se tramar algo como uma luta singular, um tête-à-têete, um duelo. Há sempre no conhecimento alguma coisa que é da ordem do duelo e que faz com que ele seja sempre singular. Este é também o caráter contraditório do conhecimento tal como é definido nos textos de Nietzsche que compõe o corpo deste artigo, que apenas aparentemente se contradizem: generalizantes e sempre singulares.

Com esta conclusão, se quis mostrar como de fato, as condições políticas, econômicas de existência não são um véu ou um obstáculo para o sujeito de conhecimento mas ao contrário, são aquilo através do que se formam os sujeitos de conhecimento e, por conseguinte, as relações que ao final vão estabelecer as verdades posta para a sociedade.

\section{REFERÊNCIAS BIBLIOGRÁFICAS}

DESCARTES, Renè. (2006). Discurso do Método. Tradução de Ciuro Mioranzxa. São Paulo: Ed. Escala Educacional.

ENGELS, Friedrich. (1979). A Dialética da Natureza. 4a edição, Rio de Janeiro, Editora Paze Terra.

ENGELS, Friedrich. (1979). Anti-Dühring. 2a. Edição, Rio de Janeiro: Editora Paz e Terra.

FOUCAULT, M. (2014). Clase del 8 de enero de 1975, En Los anormales. Curso en el Collège de France (1974-1975), trad. Horacio Pons, Buenos Aires, FCE. 
FOUCAULT, M., Castigar es lo más difícil (« Punir est la chose la plus difficile»), en Dits et écrits, v. 4, op. cit., pp. 208-210, trad. Marcelo Raffin.

FOUCAULT, M., (2010). Clase del 14 de enero de 1976, Em: Defender la sociedad. Curso en el Collège de France (1975-1976), trad. Horacio Pons, Buenos Aires, FCE.

FOUCAULT, M., "Contra las penas de sustitución” ( « Contre les peines de substitution »), en Dits et écrits, v. 4 1980-1988, Paris, Gallimard, pp. 205-207, trad. Marcelo Raffin.

FOUCAULT, M., (2008). Derecho de muerte y poder sobre la vida, capítulo 5 de La voluntad de saber, t. I de Historia de la sexualidad, trad. Ulises Guiñazú, Buenos Aires, Siglo Veintiuno Editores, $2^{\text {a }}$ edición argentina revisada.

FOUCAULT, M., (1989). El cuerpo de los condenados, capítulo 1 de Vigilar y castigar. Nacimiento de la prisión, trad. Aurelio Garzón del Camino, Buenos Aires, Siglo Veintiuno Editores.

FOUCAULT, M., (1993). Frente a los gobiernos, los derechos humanos, En La vida de los hombres infames. Ensayos sobre desviación y dominación, Montevideo/Buenos Aires, Nordan. (1993). Comunidad/Editorial Altamira, ed. y trad. Julia Varela y Fernando Alvarez Uría.

FOUCAULT, M., (2013). La verdad y las formas jurídicas, trad. Enrique Lynch, Barcelona/Buenos Aires, Gedisa.

KUHN, Thomas. (2001). A Estrutura das Revoluções Cientificas. São Paulo: Editora Perspectiva S.A, 6a. Edição.

MARX, Karl. (1985). A questão judaica. São Paulo, Editora Moraes.

PIRENNE, Henri. (1968). Histoire Economique et Sociale du Moyenage. Traduzido para o português como "História econômica e Social da Idade média", por Lycurgo Gomes da Motta, revisado por Elson Lenardon. São Paulo: Editora Mestre Jou.

TOURAINE, Alain. (1998). Igualdade e Diversidade. O sujeito democrático. Tradução de Modesto Florentino, Revisão Técnica de Antonio Penalves Rocha. Bauru, São Paulo: EDUSC. 